\title{
The Relationship Between Handball Players and Alcohol and Smoking Habits
}

\author{
by \\ Hrvoje Karnincic ${ }^{1}$, Marijana Cavala ${ }^{1}$, Nenad Rogulj ${ }^{1}$
}

\begin{abstract}
Recent studies have revealed that sport activity is a protective factor regarding smoking, but a risk factor for alcohol abuse. Considering these findings, it is necessary to investigate the occurrence of substance misuse. Sports that are associated with a substantial amount of physical/mental stress are very interesting from the perspective of substance misuse (e.g., handball). This research was performed to more closely study the population engaged in handball regarding the risk for alcohol and/or tobacco consumption. The sample of respondents consisted of 150 senior handball players who were members of 9 first-league handball clubs from Croatia and abroad. The respondents were grouped into sub-samples according to sex, age, experience, the number of weekly training sessions and their social environment (clubs). Alcohol consumption data were obtained using the AUDIT questionnaire. The differences between groups were tested using the Kruskal-Wallis and Mann-Whitney $U$ tests. The study revealed that handball players engaged in alcohol misuse, and they were grouped in the harmful drinking category (AUDIT score, 16-19 for all groups). Regarding tobacco product consumption, the risk groups were women (who smoked significantly more than men, MWU test: $Z=3.30 . p<0.001$ ), handball players with less experience (who smoked significantly more than experienced players, $M W U$ test: $Z=3.68, p<0.001$ ). Borderline significance was observed for the impact made by social environments, and age was not a significant predictor of tobacco consumption. Regarding alcohol consumption, the highest hazard group were national handball players, who drank much more than foreign players did (MWU test: Z $=2.04, p=0.04)$; however, sex, age, experience and training habits were not alcohol consumption predictors in handball. This study reveal that the typical behaviors regarding alcohol and tobacco consumption followed by the general population do not apply to handball players. Targeted prevention can be much more precisely established considering this research.
\end{abstract}

Key words: sports, substance abuse, prevention.

\section{Introduction}

Contemporary handball regularly requires players to be faster, more dynamic and capable of playing at every playing position, even for a short period of time (Bilge, 2012). In modern handball, the key element is the efficiency of a fast center player (Bilge, 2012). This position in a handball game demands from the player maximum physical fitness because it enhances the dynamics of the game itself. High-contact games also involve high-level physical preparation. The contact nature of the game characterizes all playing positions, predominantly the pivot position (Foretic et al., 2011). The largest number of handball injuries occurs primarily in contact situations during the game (Dello Iacono et al., 2017; Wedderkopp et al., 1997), and such injuries are also common in other contact sports (Burman et al., 2016). These features of modern handball increase the amount of physical stress on players, and stress is one of the main drivers of alcohol consumption in the athlete population (Lisha and Sussman, 2010). The common definition of stress states that it is a physical or a mental tension caused by factors that can alter the existing balance (Merriam-Webster, 1988). The fast tempo

1 - University of Split, Faculty of Kinesiology, Split, Croatia. 
of the game, in addition to its nature as a highcontact game, must be the physical stress generators among handball players. Handball competition generates a high level of both physical and mental stress in players (Kilic et al., 2017). Assuming that 'stress-related drinking' is one of the most frequent theses to explain the connection between sports and alcohol (Lisha and Sussman, 2010), the issue of alcohol abuse in handball should be considered. The most significant problems related to consumption of alcohol have been recorded in team sports with rugby and ice hockey at the top of the list (de Villiers et al., 2012; Du Preez et al., 2017; Gouttebarge et al., 2016, 2017). Research noted a connection between high consumption of alcohol and macho identity in rugby players (Anders et al., 2014; Gouttebarge et al., 2017; Lisha and Sussman, 2010). Out of all team sports, handball has most similarities to rugby and ice hockey (such as physical contact between players, wrestling with opponents).

Alcohol has a harmful impact on health and is the cause of death in $3.8 \%$ of cases and accounts for $4.6 \%$ of permanent disability cases, which makes it the most prominent risk factor to avoid (Rehm et al., 2009). For a long period of time, sports activity was considered a protective factor against alcohol abuse, although study results have been controversial. Several recent studies indicated that sports were a risk factor for alcohol consumption (Dietze et al., 2008) and that alcohol abuse prevention programs have already been introduced in sports environments (Kingsland et al., 2015, 2016). There are a few current hypotheses regarding why sports induce alcohol consumption, such as the explanation of stress-related drinking (Lisha and Sussman, 2010). Sport raises the levels of reward compounds (dopamine and endogenous opioids); however, when reward compounds are not activated, athletes reach for alcohol, which raises the level of these hormones (Leasure et al., 2015). Although we cannot claim with certainty what are the causes for the increased alcohol consumption among athletes, we are aware of the existing problem, yet people who are in charge in sports (e.g., coaches, managers) do not perceive it as a problem. This perception is logical because sports activity has long been considered a protective factor against alcohol abuse. As a rule, prevention and intervention methods are used to respond to these challenges (Carey et al., 2009; Nation et al., 2003; Thompson et al., 2017). Prevention and intervention in both more severe and milder cases of alcohol abuse demand different approaches and prevention programs (Savage et al., 2014). While simple preventive measures give good results in milder cases of alcohol abuse, more serious alcoholism cases have a strong genetic basis, which is more difficult to modify and for which these individuals require a different approach (Beach and Sales, 2016). Tobacco products have a status similar to alcohol, and the WHO considers tobacco one of the main health hazards. Alcohol and tobacco consumption have been connected at different levels, and studies suggest that they cannot be observed separately (Battjes, 1988). Research has shown that the hazards from the use of these substances may be greater in certain sports populations (Rolandsson and Hugoson, 2003) and that general rules cannot be applied to all sports population groups. Questions lacking answers include whether a problem of alcohol or tobacco abuse exists among handball players, how handball players might be distributed into risk groups, and whether and which prevention programs should be implemented. Alcohol and tobacco carry many health risks, and they are believed to be ergolytic for sports performance. Although parents want their children to grow up in a healthy environment, an unacceptable approach to the alcohol/tobacco problem can lead to reduced interest in that sport. This pilot study was done to provide answers to questions such as how much handball players drink/smoke, how handball players are distributed in risk groups and what characterizes handball players with substance abuse problems.

\section{Methods}

\section{Participants}

The study sample included 151 handball players with an average age of $22.8 \pm 5.1$ years. The sample sex distribution was $48.3 \%$ men and $51.7 \%$ women; in total, $70.2 \%$ of the participants were national handball players, and $29.8 \%$ were players from foreign clubs. The criterion for the selection of the sample was playing in the first or second senior league. The request was sent to 30 handball clubs (first or second league), and 
consent to the survey was given by 6 national and 3 foreign clubs. All the subjects were informed that the survey was anonymous, and that participation was voluntary. For further analyses, the sample was grouped into sub-samples according to the following: gender, age (younger $<25$ years and older $\geq 25$ years), training experience (less experienced, $<10$ years; more experienced, $\geq 10$ years), and nationality (Croatian-national clubs or foreign-international clubs). Sociodemographic data in this study included gender, age, handball experience and the number of training sessions per week. These data allowed to divide the participants into subsamples and are presented in Table 2.

\section{Measures of smoking habits and alcohol consumption}

Smoking habits were measured on a 5point Likert scale (have never smoked; smoke from time to time; smoke less than 10 cigarettes a day; smoke more than 20 cigarettes a day). Smoking on a daily basis category was calculated by summing the results of the last two claims (smoke less than 10 cigarettes a day; smoke more than 20 cigarettes a day). The Alcohol Use Disorders Identification Test (AUDIT) was used for the alcohol consumption evaluation. This survey is based on the experience of the World Health Organization (Saunders et al.,1993). The AUDIT has three subscales: drinking behavior, symptoms of alcohol dependence and hazardous consequences of drinking. The survey is a reliable measure of alcohol consumption (Bell and Britton, 2015; Lundin et al., 2015; Yee et al., 2015); it consists of ten items with scores ranging from 0 to 4 , and participants can score from a minimum of 0 to a maximum of 40 points. In this study, we used the total score from the AUDIT survey for difference analyses (Karnincic et al., 2017; Sekulic et al., 2012). Additionally, we used the AUDIT scores to group the participants into four risk groups: low risk - women from 0 to 6 , men from 0 to 7 ; hazardous drinkers - women from 7 to 15 , men from 8 to 15; harmful drinkers for men and women from 16 to 19; probable dependence for men and women from over 20 (Babor and Higgins-Biddle, 2001).

\section{Statistical Analyses}

The data was analyzed using the Statistica 13 software package (StatSoft, Tulsa, OK, USA). We calculated Cronbach alpha survey reliability variables and inter-item correlation in all the subsamples. We also calculated descriptive statistics for all the variables in all sub-samples (arithmetic mean and standard deviation in addition to minimum and maximum results). The differences between groups were tested by Kruskal-Wallis and Mann-Whitney U tests. We considered $p<$ 0.05 significant.

The study was approved by the ethical review board of the University of Split, following the Declaration of Helsinki.

\section{Results}

Table 1 displays the Cronbach alpha reliability variables and inter-item correlation for all the sub-samples.

In Table 1, it is evident that the survey fulfilled the reliability criteria in all the subsamples with alpha coefficients ranging from borderline (0.60-0.65) to excellent $(0.80-0.90)$, according to DeVellis (1991).

Table 2 presents descriptive statistical variables, arithmetic means and standard deviations (mean \pm SD) for the following variables: age, experience, the number of weekly training sessions, smoking and AUDIT along with differences among groups (Mann-Whitney U Test).

The percentages of handball players in the overall sample in the four AUDIT risk categories were as follows: low risk $0.00 \%$, hazardous drinkers $33.77 \%$, harmful drinkers $34.44 \%$ and probable dependence $31.79 \%$. No handball players belonged to the low-risk group because they were equally distributed into the other three groups.

Table 3 shows smoking habit frequencies and percentages of the handball players with the percentage of daily smokers.

Table 3 shows that the percentage of smokers on a daily basis was higher in older and less experienced players and considerably higher in foreign players. 
Table 1

Crombah Alpha reliability parameters and inter item correlation for all the sub-samples

\begin{tabular}{llll}
\hline Groups & $\mathrm{n}$ & $\alpha$ & $\mathrm{IIC}$ \\
\hline All groups & 151 & 0.77 & 0.27 \\
Male & 73 & 0.80 & 0.32 \\
Female & 78 & 0.74 & 0.24 \\
National & 106 & 0.74 & 0.24 \\
Foreigner & 45 & 0.84 & 0.38 \\
More experienced & 100 & 0.71 & 0.21 \\
Less experienced & 51 & 0.82 & 0.34 \\
Younger & 106 & 0.69 & 0.19 \\
Older & 45 & 0.78 & 0.29 \\
\hline \multicolumn{4}{c}{$\alpha-$ Crombah Alpha; IIC-Inter Item Correlation }
\end{tabular}

\section{Table 2}

Descriptive statistics, arithmetic means and standard deviations (mean $\pm S D$ ) for the following variables: age, experience, the number of weekly training sessions, smoking and AUDIT as well as differences among groups (Mann-Whitney U Test).

\begin{tabular}{|c|c|c|c|c|c|c|c|c|}
\hline & Male & Female & & & Older & Younger & & \\
\hline & $(n=73)$ & $(\mathrm{n}=78)$ & MW & J Test & $(\mathrm{n}=45)$ & $(\mathrm{n}=106)$ & MW & J Test \\
\hline & Mean \pm SD & Mean \pm SD & $\mathrm{Z}$ & $p$ & Mean \pm SD & Mean \pm SD & Z & $p$ \\
\hline Age & $24.18 \pm 6.40$ & $21.49 \pm 2.83$ & 4.59 & $<0.001$ & $29.20 \pm 3.51$ & $20.39 \pm 2.31$ & 9.82 & $<0.001$ \\
\hline Experience & $13.85 \pm 5.80$ & $11.34 \pm 3.01$ & 1.40 & $=0.16$ & $17.52 \pm 4.56$ & $10.57 \pm 3.13$ & 7.85 & $<0.001$ \\
\hline Training & $7.60 \pm 3.04$ & $5.20 \pm 1.76$ & 2.54 & $=0.01$ & $7.49 \pm 2.76$ & $5.89 \pm 2.60$ & 3.36 & $<0.001$ \\
\hline Smoking & $2.08 \pm 1.29$ & $2.41 \pm 1.27$ & 3.30 & $<0.001$ & $2.18 \pm 1.30$ & $2.28 \pm 1.29$ & -0.40 & 0.69 \\
\hline \multirow[t]{4}{*}{ Audit } & $18.45 \pm 4.88$ & $17.45 \pm 4.96$ & -1.64 & $=0.10$ & $17.98 \pm 4.64$ & $17.93 \pm 5.08$ & 0.14 & 0.89 \\
\hline & National & Foreigner & & & More experienced & Less experienced & & \\
\hline & $(\mathrm{n}=106)$ & $(\mathrm{n}=45)$ & \multicolumn{2}{|c|}{ MWU Test } & $(\mathrm{n}=100)$ & $(\mathrm{n}=51)$ & \multicolumn{2}{|c|}{ MWU Test } \\
\hline & Mean \pm SD & Mean \pm SD & Z & $p$ & Mean \pm SD & Mean \pm SD & Z & $p$ \\
\hline Age & $22.38 \pm 5.57$ & $22.22 \pm 3.92$ & 0.25 & $=0.80$ & $24.89 \pm 4.60$ & $19.12 \pm 3.56$ & 8.11 & $<0.001$ \\
\hline Experience & $12.73 \pm 4.80$ & $12.15 \pm 4.17$ & 0.89 & $=0.37$ & $15.32 \pm 3.66$ & $7.90 \pm 1.96$ & 10.57 & $<0.001$ \\
\hline Training & $6.39 \pm 2.32$ & $6.24 \pm 3.43$ & 1.21 & $=0.23$ & $6.94 \pm 2.76$ & $5.33 \pm 2.38$ & -0.41 & $=0.68$ \\
\hline Smoking & $2.12 \pm 1.29$ & $2.50 \pm 1.26$ & -1.77 & $=0.08$ & $2.21 \pm 1.29$ & $2.32 \pm 1.30$ & 3.68 & $<0.001$ \\
\hline Audit & $18.53 \pm 5.00$ & $16.80 \pm 4.68$ & 2.04 & $=0.04$ & $17.91 \pm 4.52$ & $18.00 \pm 5.63$ & 0.18 & $=0.86$ \\
\hline
\end{tabular}

MWU - Mann-Whitney U test; Z - test score; $p$ - significance level 
Table 3

Smoking habits of handball players' frequencies and percentage with the percentage of daily smokers

\begin{tabular}{|c|c|c|c|c|c|c|c|c|c|c|c|}
\hline & \multicolumn{2}{|c|}{$\begin{array}{c}\text { Never } \\
\text { smoked }\end{array}$} & \multicolumn{2}{|c|}{$\begin{array}{c}\text { Quit } \\
\text { smoking }\end{array}$} & \multicolumn{2}{|c|}{$\begin{array}{l}\text { Smoking } \\
\text { from time to } \\
\text { time }\end{array}$} & \multicolumn{2}{|c|}{$\begin{array}{l}\text { Smoking } \\
\text { more than } 10\end{array}$} & \multicolumn{2}{|c|}{$\begin{array}{l}\text { Smoking } \\
\text { more than } \\
20\end{array}$} & \multirow{2}{*}{$\begin{array}{c}\text { Percentage } \\
\text { of daily } \\
\text { smokers }\end{array}$} \\
\hline & $\mathrm{f}$ & $\%$ & $\mathrm{f}$ & $\%$ & $\mathrm{f}$ & $\%$ & $\mathrm{f}$ & $\%$ & $\mathrm{f}$ & $\%$ & \\
\hline All groups $(n=151)$ & 66.0 & 44.0 & 14.0 & 9.3 & 34.0 & 22.7 & 32.0 & 21.3 & 4.0 & 2.7 & 24.0 \\
\hline Younger $(n=106)$ & 20.0 & 44.4 & 8.0 & 17.8 & 37.0 & 20.0 & 5.0 & 11.1 & 3.0 & 6.7 & 17.8 \\
\hline Older $(n=45)$ & 53.0 & 54.0 & 59.0 & 5.0 & 28.0 & 24.3 & 27.0 & 23.5 & 1.0 & 0.9 & 24.4 \\
\hline More experienced $(n=100)$ & 46.0 & 46.0 & 12.0 & 12.0 & 20.0 & 20.0 & 19.0 & 19.0 & 3.0 & 3.0 & 22.0 \\
\hline Less experienced $(n=51)$ & 27.0 & 45.0 & 2.0 & 3.3 & 17.0 & 28.3 & 13.0 & 21.7 & 1.0 & 1.7 & 23.4 \\
\hline Male $(\mathrm{n}=73)$ & 40.0 & 54.8 & 6.0 & 8.2 & 11.0 & 15.1 & 14.0 & 19.2 & 2.0 & 2.7 & 21.9 \\
\hline Female $(\mathrm{n}=78)$ & 29.0 & 37.2 & 8.0 & 10.3 & 24.0 & 30.8 & 15.0 & 19.2 & 2.0 & 2.6 & 21.8 \\
\hline National $(n=106)$ & 55.0 & 51.9 & 7.0 & 6.6 & 23.0 & 21.7 & 18.0 & 17.0 & 3.0 & 2.8 & 19.8 \\
\hline International $(n=45)$ & 18.0 & 33.3 & 7.0 & 13.0 & 14.0 & 25.9 & 14.0 & 25.9 & 1.0 & 1.9 & 27.8 \\
\hline
\end{tabular}

$f$-frequencies; \% - percentage

\section{Discussion}

As shown in Table 1, in competitive handball, the situation appears rather serious regarding alcohol consumption. According to the survey results, no player fell into the category of harmless drinking (low risk); rather, all handball players were equally distributed among the three following categories: hazardous drinking (33.77\%), harmful drinking (34.44\%) and probable dependence $(31.79 \%)$. There was no difference in alcohol consumption related to gender; even if men drank slightly more, the difference was not significant (men, 18.45\%; women, 17.45\%). According to previous studies, men globally drink more than women do (Hull et al., 2016); however, there is a growing tendency of a decreasing difference between genders (Bloomfield et al., 2001; McPherson et al., 2004). The tendency is 
known as the "gender convergence hypothesis" (Bloomfield et al., 2001), and we may assume that the lack of significant differences between the genders is caused by this phenomenon. There were no significant differences related to age, even though the groups were composed of younger or older players because the heaviest drinkers are aged 18-25 (Nelson et al., 2008). That is, the younger participants were in the risk group, but the older ones were not because they were aged 25 and older. According to previous studies, age and gender are variables that have a significant impact on alcohol consumption (Boyle et al., 2016; Jackson et al., 2012; Karam et al., 2007). Yet the rules applied to the general population cannot be applied to the sub-population of handball players.

Studies have revealed that a higher sport engagement level is associated with a higher level of alcohol consumption (Martens et al., 2006). According to this study, more experienced athletes are expected to drink more. There were no significant differences between more and less experienced handball players in this research; however, less experienced players drank slightly more (less experienced players, $17.91 \%$ vs. more experienced players, $18.00 \%$ ). Furthermore, older handball players drank slightly more (older, $17.89 \%$ vs. younger, $17.93 \%)$. The percentage differences are minimal, but illogical; i.e., if older players drink more, then the more experienced players should have drunk more, which was not the case in our study. The same sample can be divided on another basis. Conventionally, older handball players are also more experienced; however, perhaps the older players with less experience in our group started playing handball later than other older handball players. We may assume that earlier/later involvement into a sport activity can be related to alcohol consumption and there are numerous reasons to support this assumption. Experienced players are better at coping with stress (Stone et al., 2017), which is one of the most frequent causes leading to alcohol consumption among athletes. Future research should consider the connection between alcohol and sports experience more closely. An important thesis of our work is that the alcohol issue among athletes is stress related. This research, in which we measured high levels of alcohol consumption among high-stress handball players, did not negate this claim. High levels of alcohol consumption were found among team sport athletes (Denault and Poulin, 2018) along with a high level of alcohol-related disease (Kontro et al., 2017). Kontro et al. (2017) have found that team and combat sports have the most problems with alcohol abuse. Combat sports and handball are sports with substantial physical contact and the levels of physical stress are very high (ReynosoSanchez et al., 2017). Compared to the players from the international league, it is evident that players from the Croatian league drank considerably more (Table 1). Alcohol consumption varies among different entities (Degenhardt et al., 2008), and special attention should be paid to prevention among national handball players.

Regarding smoking habits, sports activity is clearly a protective factor; the percentage of smokers among athletes is much lower than that in the general population (Alaranta et al., 2006). Certain studies disregard deleterious effects caused by smoking (Myers, 2010; Colebatch, 1985); however, athletes are well aware of the way in which tobacco influences physical fitness. According to WHO data from 2011, the largest number of smokers is from Europe (28\%); the USA is in the middle of the scale at the level of 20.0\% (Ramstrom and Wikmans, 2014; WHO, 2014). In Balkan countries, the percentage ranges between 27.5 and 34.7; in Croatia, it is $29 \%$, although this percentage is tending to increase (Ng et al., 2014; WHO, 2014). The percentage of smokers on a daily basis in this study ranged from 17.8 to $28.8 \%$, depending on the sub-sample. According to this research, women smoked considerably more than men did (MWU test: $\mathrm{Z}=$ 3.30, $p<0.001$ ). Observing exclusively the group that smoked on a daily basis, the results were nearly the same (women, 21.9\%; men, 21.8\%). Significant differences were observed for the category of those who smoked from time to time, with men reaching $15.1 \%$ and women $30.8 \%$. Another unexpected result was the large percentage of foreign daily smokers $(27.8 \%)$, while in national players, this percentage reached $19.8 \%$. The significant difference between these groups is approximately $p=0.04$. The reason for this finding rests with the fact that an Austrian club is included in international clubs, in which the number of everyday smokers is extremely 
high and reaches $44.0 \%$ (WHO, 2014). There were no significant differences between younger and older handball players regarding tobacco consumption. In this study, handball players smoked more than athletes from other team sports. Recent studies have shown that team sports are associated with a lower risk of tobacco smoking, but a greater risk of using smokeless tobacco (Parent et al., 2016). Smokeless tobacco is very popular in some countries, but not in Croatia, where only $1.9 \%$ of young people and $0.6 \%$ of adults consume it (WHO, 2017). However, there were considerably more smokers who smoked on a daily basis among the older smokers (older, 24.4\%; younger, $17.8 \%$ ). The lack of a significant difference can be attributed to the category of smoking from time to time, in which the younger participants reached $37 \%$ and the older ones $28 \%$. The increase in the smoking from time to time category is not surprising. Studies have revealed that players in this category do not consider themselves smokers; frequently, this status is merely a transition phase towards quitting and will eventually lessen the health hazards (Schane et al., 2010). It has been also shown that light and intermittent tobacco smokers (LITS) are mostly young individuals, women, singles and members of ethnic minorities (Schane et al., 2010). Women and young handball players are highly represented in the LITS category. An increasing number of LITS leading to a lower number of daily smokers is a positive tendency; however, it is a negative tendency if the former number increases due to a lower number of nonsmokers. The increasing trend of LITS should be followed and analyzed because this phenomenon can be viewed concurrently as positive or negative.

Contribution and limitations of the study

This research showed that alcohol consumption and tobacco use should be persistently monitored because trends tend to change. Similar analyses should be conducted separately in all sports and on larger samples, the latter of which is a limitation of this study. The lack of continuous control of the given variables led to serious issues in some groups (as in the research conducted by Ronaldson in 2003), which could have been avoided if we had reacted preventively (Rolandsson and Hugoson, 2003). Based on this knowledge, we must suggest an extremely serious approach and further studies to determine the most adequate intervention and preventive measures. Finally, national associations can be advised to introduce obligatory oversight of these phenomena and to bear the responsibility to intervene and prevent them, depending on the need and the obtained results.

\section{Conclusion}

The study revealed that very few rules on the consumption of alcohol and tobacco applied in the global population may be transferred to the handball player sub-population. Women and foreign players with less training experience constitute the current profile of the risk group regarding the consumption of tobacco products. The situation is more complex regarding alcohol issues. According to this research, no players fell into the low-risk category, and studies suggest interventions and prevention for all other categories in addition to constant monitoring of situation development. The results regarding women were very unexpected considering that they smoked more than men and consumed alcohol as equally as men; i.e., positive sex differences related to harmful substance consumption are gradually disappearing, and women must become more frequently incorporated into prevention programs.

\section{References}

Alaranta A, Alaranta H, Patja K, Palmu P, Prattala R, Martelin T, Helenius I. Snuff use and smoking in Finnish olympic athletes. Int J Sports Med, 2006; 27(7): 581-586. doi:10.1055/s-2005-865826

Babor T, Higgins-Biddle JC. Brief intervention for hazardous and harmful drinking: A manual for use in primary care. Geneva, Switzerland: World Health Organisation; 2001

Battjes RJ. Smoking as an Issue in Alcohol and Drug-Abuse Treatment. Addict Behav, 1988; 13(3): 225-230. doi:10.1016/0306-4603(88)90049-4 
Beach S, Sales JMD. Refining Prevention: Genetic and Epigenetic Contributions: Frontiers Media SA; 2016

Bell S, Britton A. Reliability of a retrospective decade-based life-course alcohol consumption questionnaire administered in later life. Addiction, 2015; 110(10): 1563-1573. doi:10.1111/add.13012

Bilge M. Game Analysis of Olympic, World and European Championships in Men's Handball. J Hum Kinet, 2012; 35: 109-118. doi:10.2478/v10078-012-0084-7

Bloomfield K, Gmel G, Neve R, Mustonen H. Investigating Gender Convergence in Alcohol Consumption in Finland, Germany, The Netherlands, and Switzerland: A Repeated Survey Analysis. Subst Abus, 2001; 22(1): 39-53. doi:10.1080/08897070109511444

Boyle SC, LaBrie JW, Froidevaux NM, Witkovic YD. Different digital paths to the keg? How exposure to peers' alcohol-related social media content influences drinking among male and female first-year college students. Addict Behav, 2016; 57: 21-29. doi:10.1016/j.addbeh.2016.01.011

Burman E, Lysholm J, Shahim P, Malm C, Tegner Y. Concussed athletes are more prone to injury both before and after their index concussion: a data base analysis of 699 concussed contact sports athletes. BMJ Open Sport Exerc Med, 2016; 2(1): e000092. doi:10.1136/bmjsem-2015-000092

Carey KB, Scott-Sheldon LA, Elliott JC, Bolles JR, Carey MP. Computer-delivered interventions to reduce college student drinking: a meta-analysis. Addiction, 2009; 104(11): 1807-1819. doi:10.1111/j.13600443.2009.02691.x

Colebatch HJ, Greaves IA, Ng CK. Pulmonary distensibility and ventilatory function in smokers. Bulletin europeen de physiopathologie respiratoire, 1985; 21(5): 439-447

Degenhardt L, Chiu W-T, Sampson N, Kessler RC, Anthony JC, Angermeyer M, Bruffaerts R, de Girolamo G, Gureje O, Huang Y, Karam A, Kostyuchenko S, Lepine JP, Mora MEM, Neumark Y, Ormel JH, Pinto-Meza A, Posada-Villa J, Stein DJ, Takeshima T, Wells JE. Toward a Global View of Alcohol, Tobacco, Cannabis, and Cocaine Use: Findings from the WHO World Mental Health Surveys. PLoS Medicine, 2008; 5(7): e141

Dello Iacono A, Eliakim A, Padulo J, Laver L, Ben-Zaken S, Meckel Y. Neuromuscular and inflammatory responses to handball small-sided games: the effects of physical contact. Scand J Med Sci Sports, 2017; 27(10): 1122-1129. doi:10.1111/sms.12755

Denault AS, Poulin F. A Detailed Examination of the Longitudinal Associations Between Individual and Team Sports and Alcohol Use. Addictive Behaviors, 2018; 78: 15-21. doi:10.1016/j.addbeh.2017.10.019

de Villiers A, Steyn NP, Draper CE, Fourie JM, Barkhuizen G, Lombard CJ, Dalais L, Abrahams Z, Lambert EV. "HealthKick": Formative assessment of the health environment in low-resource primary schools in the Western Cape Province of South Africa. Bmc Public Health, 2012; 12: 11. doi:10.1186/1471-2458$12-794$

Dietze PM, Fitzgerald JL, Jenkinson RA. Drinking by professional Australian Football League (AFL) players: prevalence and correlates of risk. Med J Aust, 2008; 189(9): 479-483

Du Preez EJ, Graham KS, Gan TY, Moses B, Ball C, Kuah DE. Depression, Anxiety, and Alcohol Use in Elite Rugby League Players Over a Competitive Season. Clinical Journal of Sport Medicine, 2017; 27(6): 530535

Foretic N, Karnincic H, Uljevic O. The influence of the wrestling technique on contact efficiency of young male team handball players. Archives of Budo, 2011; 7(2): 5

Gouttebarge V, Aoki H, Lambert M, Stewart W, Kerkhoffs G. A history of concussions is associated with symptoms of common mental disorders in former male professional athletes across a range of sports. Physician and Sportsmedicine, 2017; 45(4): 443-449. doi:10.1080/00913847.2017.1376572

Gouttebarge V, Hopley P, Kerkhoffs G, Verhagen E, Viljoen W, Wylleman P, Lambert MI. Symptoms Of Common Mental Disorders In Professional Rugby: An International Observational Descriptive Study. Int J Sports Med, 2017; 38(11): 864-870. doi:10.1055/s-0043-114010

Gouttebarge V, Kerkhoffs G, Lambert M. Prevalence and determinants of symptoms of common mental disorders in retired professional Rugby Union players. Eur J Sport Sci, 2016; 16(5): 595-602. doi:10.1080/17461391.2015.1086819

Jackson CA, Henderson M, Frank JW, Haw SJ. An overview of prevention of multiple risk behaviour in adolescence and young adulthood. J Public Health (Oxf), 2012; 34 Suppl 1: i31-40. 
doi:10.1093/pubmed/fdr113

Karam E, Kypri K, Salamoun M. Alcohol use among college students: an international perspective. Current Opinion in Psychiatry, 2007; 20(3): 213-221

Karnincic H, Drasinac G, Kardum G. Engagement in Sports Activity as an Important Factor Among Sports Activity, Religiosity and Alcohol Consumption. 8th International Scientific Conference on Kinesiology, 2017; 516-520

Kilic O, Aoki H, Haagensen R, Jensen C, Johnson U, Kerkhoffs G, Gouttebarge V. Symptoms of common mental disorders and related stressors in Danish professional football and handball. Eur J Sport Sci, 2017; 1-7. doi:10.1080/17461391.2017.1381768

Kingsland M, Wiggers JH, Vashum KP, Hodder RK, Wolfenden L. Interventions in sports settings to reduce risky alcohol consumption and alcohol-related harm: a systematic review. Syst Rev, 2016; 5: 12. doi:10.1186/s13643-016-0183-y

Kingsland M, Wolfenden L, Tindall J, Rowland BC, Lecathelinais C, Gillham KE, Dodds P, Sidey MN, Rogerson JC, McElduff P, Crundall I, Wiggers JH. Tackling risky alcohol consumption in sport: a cluster randomised controlled trial of an alcohol management intervention with community football clubs. Journal of Epidemiology and Community Health, 2015; 69(10): 993-999. doi:10.1136/jech-2014204984

Kontro TK, Sarna S, Kaprio J, Kujala UM. Use of Alcohol and Alcohol-Related Morbidity in Finnish Former Elite Athletes. Med Sci Sports Exerc, 2017; 49(3): 492-499. doi:10.1249/mss.0000000000001137

Leasure JL, Neighbors C, Henderson CE, Young CM. Exercise and Alcohol Consumption: What We Know, What We Need to Know, and Why it is Important. Front Psychiatry, 2015; 6: 156. doi:10.3389/fpsyt.2015.00156

Lisha NE, Sussman S. Relationship of high school and college sports participation with alcohol, tobacco, and illicit drug use: a review. Addict Behav, 2010; 35(5): 399-407. doi:10.1016/j.addbeh.2009.12.032

Lundin A, Hallgren M, Balliu N, Forsell Y. The Use of Alcohol Use Disorders Identification Test (AUDIT) in Detecting Alcohol Use Disorder and Risk Drinking in the General Population: Validation of AUDIT Using Schedules for Clinical Assessment in Neuropsychiatry. Alcoholism-Clinical and Experimental Research, 2015; 39(1): 158-165. doi:10.1111/acer.12593

Martens MP, Dams-O'Connor K, Beck NC. A systematic review of college student-athlete drinking: Prevalence rates, sport-related factors, and interventions. J Subst Abuse Treat, 2006; 31(3): 305-316. doi:10.1016/j.jsat.2006.05.004

McPherson M, Casswell, S, Pledger M. Gender convergence in alcohol consumption and related problems: issues and outcomes from comparisons of New Zealand survey data. Addiction, 2006; 99(6): 738-748. doi:10.1111/j.1360-0443.2004.00758.x

Merriam-Webster I. Webster's ninth new collegiate dictionary: Merriam-Webster; 1988

Myers KA. Holiday reading: Cigarette smoking: an underused tool in high-performance endurance training. Cmaj, 2010; 182(18): E867-869. doi:10.1503/cmaj.100042

Nation M, Crusto C, Wandersman A, Kumpfer KL, Seybolt D, Morrissey-Kane E, Davino K. What works in prevention. Principles of effective prevention programs. Am Psychol, 2003; 58(6-7): 449-456

Nelson MC, Story M, Larson NI, Neumark-Sztainer D, Lytle LA. Emerging adulthood and college-aged youth: an overlooked age for weight-related behavior change. Obesity (Silver Spring), 2008; 16(10): 2205-2211. doi:10.1038/oby.2008.365

Ng M, Freeman MK, Fleming TD, Robinson M, Dwyer-Lindgren L, Thomson B, Wollum A, Sanman E, Wulf S, Lopez AD, Murray CJL, Gakidou E. Smoking prevalence and cigarette consumption in 187 countries, 1980-2012. Jama, 2014; 311(2): 183-192. doi:10.1001/jama.2013.284692

Ramstrom L, Wikmans T. Mortality attributable to tobacco among men in Sweden and other European countries: an analysis of data in a WHO report. Tob Induc Dis, 2014; 12(1): 14. doi:10.1186/1617-9625$12-14$

Rehm J, Mathers C, Popova S, Thavorncharoensap M, Teerawattananon Y, Patra J. Global burden of disease and injury and economic cost attributable to alcohol use and alcohol-use disorders. Lancet, 2009; 373(9682): 2223-2233. doi:10.1016/s0140-6736(09)60746-7 
Reynoso-Sanchez LF, Flores JRH, Garcia-Davila M, Taraco AGR, Sanchez JCJ, Lopez-Walle JM, HernandezCruz G. Cortisol and Recovery-Stress During a Competitive Period in Handball Players. Revista De Psicologia Del Deporte, 2017; 26: 125-131

Rolandsson M, Hugoson A. Changes in tobacco habits - A prospective longitudinal study of tobacco habits among boys who play ice hockey. Swedish Dental Journal, 2003; 27(4): 175-184

Savage JE, Neale Z, Cho SB, Donovan KK, Hancock L, Kalmijn J, Smith TL, Shuckit MA. Donovan MD, Dick DM. Level Of Response to Alcohol as a Factor for Targeted Prevention in College Students. Alcoholism-Clinical and Experimental Research, 2014; 38: 128A-128A

Schane RE, Ling PM, Glantz SA. Health effects of light and intermittent smoking: a review. Circulation, 2010; 121(13): 1518-1522. doi:10.1161/circulationaha.109.904235

Sekulic D, Ostojic M, Ostojic Z, Hajdarevic B, Ostojic L. Substance abuse prevalence and its relation to scholastic achievement and sport factors: an analysis among adolescents of the Herzegovina-Neretva Canton in Bosnia and Herzegovina. Bmc Public Health, 2012; 12: doi:10.1186/1471-2458-12-274

Stone JD, Kreutzer A, Mata JD, Nystrom MG, Jagim AR, Jones MT, Oliver JM. Changes in Creatine Kinase and Hormones over the Course of an American Football Season. J Strength Cond Res, 2017; doi:10.1519/jsc.0000000000001920

Sønderlund AL, O'Brien K, Kremer P, Rowland B, De Groot F, Staiger P, Zinkijevicz L, Miller PG. The association between sports participation, alcohol use and aggression and violence: A systematic review. J Sci Med Sport, 2014; 17(1): 2-7. doi:10.1016/j.jsams.2013.03.011

Thompson HM, Previte J, Kelly S, Kelly AB. Examining alcohol management practices in community sports clubs: a systems approach. Journal of Social Marketing, 2017; 7(3): 250-267. doi:10.1108/jsocm-04-20170026

Wedderkopp N, Kaltoft M, Lundgaard B, Rosendahl M, Froberg K. Injuries in young female players in European team handball. Scand J Med Sci Sports, 1997; 7(6): 342-347

WHO - World Health Organization. European Tobacco Control Status Report 2014. From: http://www.euro.who.int/_data/assets/pdf_file/0009/248418/European-Tobacco-Control-StatusReport-2014-Eng.pdf?ua\%3D1

WHO - World Health Organization. WHO report on the global tobacco epidemic, 2017 - Country profile Croatia. From: http://www.who.int/tobacco/surveillance/policy/country_profile/hrv.pdf?ua=1

Yee A, Adlan ASA, Rashid RR, Habil H, Kamali K. Validation of the alcohol use disorders identification test (AUDIT) - Bahasa Malaysia version among a group of alcohol users. Journal of Substance Use, 2015; 20(4): 229-233. doi:10.3109/14659891.2014.894588

\section{Corresponding author:}

\section{Hrvoje Karnincic Ph.D}

University of Split, Faculty of Kinesiology

Teslina 6, Split - 21000, Croatia

Phone : +385 21302440

Email: hrvojek@kifst.hr 